\title{
The Early Mesolithic in Southern Scandinavia and Northern Germany
}

\author{
Mikkel Sørensen, Harald Lübke and Daniel Groß
}

\section{Introduction}

Excavations were undertaken at Star Carr by Clark in order to find a British counterpart to the well-known European sites such as Mullerup, Holmegård, Sværdborg, Lundby, Duvensee and Ageröd (Clark 1954, 179). Clark noted that there was a certain cultural homogeneity across the North European plain at this time when Britain was still joined to the Continent. As it turned out, the material culture from Star Carr proved to be earlier in date compared to these other sites, which indicated to Clark that Star Carr belonged to a distinct phase of the Early Mesolithic, termed in Northwest Europe the Maglemose culture (Clark 1954, 180).

Before the development of radiocarbon dating in the 1950s, the dating of the Early Maglemose culture was carried out using relative stratigraphies of pollen and plant macrofossils. Open landscapes with juniper, followed by birch and pine forests represented what was defined as the 'Preboreal' period, whilst a varied deciduous forest characterized by hazel, alder, lime and oak marked the transition to the 'Boreal' period. In Southern Scandinavia, the Preboreal period is dated from c. 9600 BC to c. 8000 BC. Yet the transition to the deciduous forest occurred earlier in the south-east part of the region compared to the north-west meaning that the vegetation, the fauna and the Mesolithic economy must have varied from east to west during the Late Preboreal period.

Clark noted that it was difficult to establish the context of Star Carr within the cultural sequence of Northwest Europe due to the paucity of Preboreal sites in the archaeological record. As such, he examined Klosterlund by the shore of the former lake Bølling in Jutland, Denmark, as a comparator though noted that this assemblage consisted of only flint and stone objects. Since then, dating methods have improved and more sites of this period have come to light. However, for the 800 or so years of occupation at Star Carr there are still relatively few sites of this period in Northwest Europe, especially when compared to other periods, and of these, very few have organic preservation. This chapter sets out the details of some of these sites; these have been mapped in Figure 12.1, which also shows the reconstruction of the ancient shoreline of the North Sea at the time.

How to cite this book chapter:

Sørensen, M., Lübke, H. and Groß, D. 2018. The Early Mesolithic in Southern Scandinavia and Northern Germany. In: Milner, N., Conneller, C. and Taylor, B. (eds.) Star Carr Volume 1: A Persistent Place in a Changing World, pp. 305-329. York: White Rose University Press. DOI: https://doi.org/10.22599/book1.1. Licence: CC BY-NC 4.0 


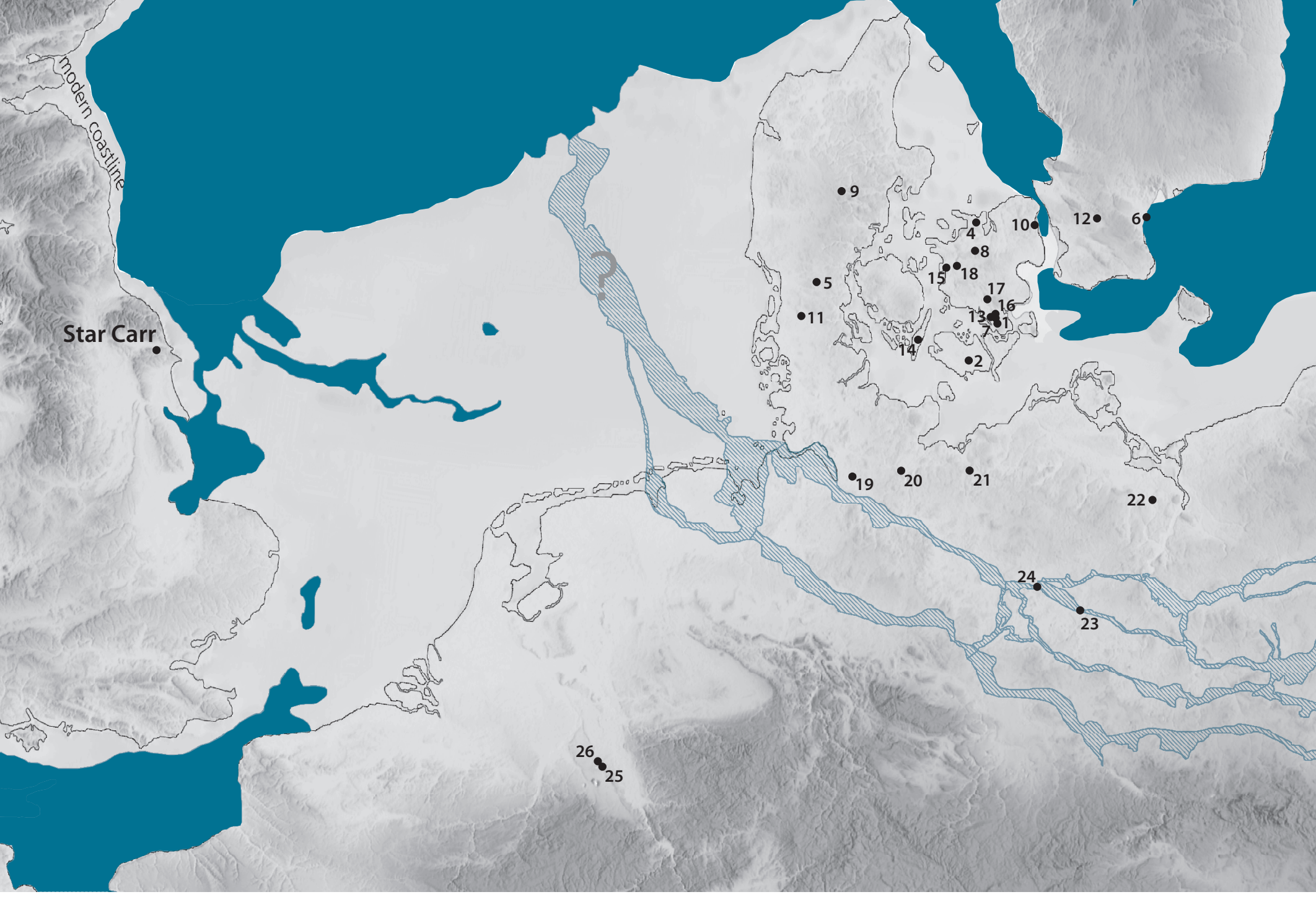

Figure 12.1: Southern Scandinavian and Northern German Maglemose sites. Preboreal sites: 1. Lundby kettle hole lake deposits (Hansen et al. 2004; Jessen et al. 2015); 2. Skottemarke elk deposits (Møhl 1980; Sørensen 1980; Fischer 1996); 3. Favrbo elk deposits (Møhl 1980); 4. Vig aurochs deposit (Hartz and Winge 1906); 5. Nørregaard VI (Sørensen and Sternke 2004); 6. Årup contexts 1, 2 and 3 (Karsten and Nilsson 2006); 7. Barmosen I (Johansson 1990); 8. Bjergby Enge (Andersen 1980); 9. Klosterlund (Mathiassen 1937; Petersen 1966); 10. Gl. Ullerød (Jensen 2002); 11. Draved 611, 604s and 332 (Sobotta 1991); 12. Henninge boställe (Althin 1954); 13. Hasbjerg II (Johansson 1990); 14. Flaadet (Skaarup 1979); 15. Mullerup; 16. Sværdborg; 17. Holmegaard; 18. Åmosen; 19. Pinnberg 7 (Rust 1958a); 20. Duvensee; 21. Hohen Viecheln (Schuldt 1961); 22. Rothenklempenow 17 (Schacht and Bogen 2001); 23. Potsdam-Schlaatz (Benecke et al. 2002); 24. Friesack (Gramsch 2002); 25. Bedburg-Königshoven (Street 1989); 26. Mönchengladbach-Geneicken (Heinen 2014). The map illustrates the land masses at the Pleistocene/Holocene transition (compiled by Grimm 2009 after Björck 1995a; Boulton et al. 2001; Lundqvist and Wohlfahrt 2001; Weaver et al. 2003; Clarke et al. 2004; Brooks 2006b; Ivy-Ochs et al. 2006; with further additions from Woldstedt 1956; Björck 1995b; Björck 1996; Zahn 1996; Coope et al. 1998, figure 4H; Kobusiewicz 1999, 190; Gaffney et al. 2007, 3-7 and 71) (Copyright Daniel Groß, CC BY-NC 4.0).

\section{The Maglemose culture in Northwest Europe}

\section{The discovery and definition of the Maglemose Culture}

Before the Maglemose culture was defined, Stone Age archaeology was already well established in Southern Scandinavia, arising from the discovery of coastal shell middens which were investigated by the 'Kitchen midden commissions' and dated to the Ertebølle culture (Late Mesolithic). However, in 1900 a new type of site 
was discovered by the National Museum trained botanist and archaeologist Georg Frederik Ludvig Sarauw (1862-1928). On the 8th of June 1900 he was sent by the National Museum to the bog of Mullerup in Western Zealand. Here a local teacher (M. J. Mathiassen) had reported unusual, well-preserved finds of ancient bones, charcoal and lithics from the bog during peat cutting. Sarauw immediately undertook an excavation to an unusually high quality standard for the time, examining the geological layers and botany within the bog as well as the spatial distribution of the artefacts and their stratigraphic position. In 1903 he published a thorough account of this excavation and coined the term 'Maglemose'. He argued that what he had found was not an Ertebølle cultural site but something older: an inland culture that lived within large bogs and had an economy based on aquatic and terrestrial resources (Sarauw 1903). The culture was first called 'Mullerup', after the nearby village; however, as the local bog was called 'Maglemose' the culture was finally named after the bog. In fact, 'Maglemose' means 'large bog' in Danish and there are many Maglemose place names all over Southern Scandinavia. Thus, in the Danish language the Maglemose culture simply means the Stone Age culture found in large bogs. In 1904 a new site was found in the Maglemose bog of Mullerup just north of the first one. This was investigated in the same year and then again in 1915.

Following this, the extremely rich and well-preserved site clusters of Southern Zealand, the Sværdborg bog (Friis Johansen 1919), Holmegård bog (Broholm 1924) and Lundby Mose, were found and became of great importance for the understanding of the Early Maglemose culture due to their unique preservation of organic materials. On Jutland, the Klosterlund site was excavated as a part of Therkel Mathiassen's large-scale survey of the inland river systems (Mathiassen 1937). Mathiassen took a landscape approach and presented the 'Gudenaa culture'; a concept that is now viewed as a conglomerate of both Early and Late Mesolithic assemblages. Yet Mathiassen did not ascribe the Klosterlund site to the Gudenaa culture as its assemblage was clearly different to other Mesolithic sites of the region. Furthermore, analyses of the stratigraphy and pollen demonstrated that the assemblage was Preboreal. Thus the material from the Klosterlund site became the first large Preboreal assemblage in Southern Scandinavia.

Apart from isolated stray and surface finds, the first Early Mesolithic bog sites outside Southern Scandinavia were discovered almost concurrently in Northern Germany at Friesack, Brandenburg, by Max Schneider (Schneider 1932) and at Duvensee, Schleswig-Holstein, by geologist Karl Gripp and archaeologist Gustav Schwantes (Schwantes et al. 1925; Schwantes 1928). In 1938, when Hermann Schwabedissen finished the first synthesis of the Mesolithic in Western Northern Germany (Schwabedissen 1944), Alfred Rust began excavating the Early Mesolithic site of Pinnberg (Rust 1958a). Based on the work from Sarauw, a chronological framework for the Maglemosian was already established before the Second World War. After the war, Early Mesolithic research was revived when Schwabedissen commenced new investigations at the Duvensee bog in 1946 (Schwabedissen 1949) and Ewald Schuldt excavated the newly discovered site of Hohen Viecheln in Mecklenburg-Vorpommern from 1953-1955 (Schuldt 1961).

In the following decades of the 20th century, research on the Early Mesolithic in Northeastern Germany has been especially influenced by Bernhard Gramsch. In addition to his thesis on the Mesolithic in the lowlands between the Elbe and Oder (Gramsch 1973), the resumption of excavations of Early Mesolithic sites near Friesack were particularly important for the understanding of the Maglemose culture (Gramsch 1987a; Gramsch 2002). In Western Germany Klaus Bokelmann continued the research on Mesolithic sites at Duvensee from 1966-2001 and discovered nearly 20 new, mainly Early Mesolithic bog sites (Bokelmann 1971; Bokelmann 2012). Further important Early Mesolithic sites with organic remains investigated in the late 20th century include Bedburg-Königshoven, North Rhine-Westphalia (Street 1991), Rothenklempenow, MecklenburgVorpommern (Schacht 1993; Kaiser 2003) and the kill site of an aurochs at Potsdam Schlaatz, Brandenburg (Gramsch 1987a; Gramsch 1987b). Another site with strong potential is the recently discovered site of Mönchengladbach-Geneicken (Heinen 2014).

\section{Dating the Maglemose culture}

The first attempt to develop a systematic relative chronology of the Maglemose culture from its inventory by typological analysis was made by Carl J. Becker. In 1952 he ordered microlith types, blade core morphology and scraper types into five phases (Becker 1952). This model was reviewed and expanded by Brinch Petersen who, by mainly studying the microliths and their frequencies, suggested a division into six phases (Petersen 1973). More recently, a study of the Maglemose culture lithic blade technologies defined seven different concepts 
of production typical to four different technological phases, the first two of which appear in the Preboreal (Sørensen 2006). Thus today the lithic artefacts of the Maglemose culture are generally relatively dated by microliths and lithic blade technology.

However, in recent years studies of bone tool technology and the possibility of absolute dating by the AMS radiocarbon method have demonstrated that the material has great potential for both relative and absolute dating (David 1999; David 2006; Andersen and Petersen 2009; David 2009; David and Sørensen 2016). For example, barbed bone points and antler adzes are examples of types of artefacts that can be relatively dated in terms of their morphology and from which species they are made. However, a problem in Southern Scandinavia is that relative chronologies are generally developed on material from Eastern Denmark (Zealand) where more sites have been excavated and the best preservation is encountered. Studies of Maglemose cultural material in Western Denmark (Jutland) show that the Later Maglemose culture in particular does not necessarily follow the Eastern Danish development (Andersen and Sterum 1971; Sørensen in press). Moreover, from the island of Bornholm, Nielsen (2001) proposed a regional relative chronology based on microlith morphologies of four phases that partly differ from the generally suggested microlith chronology.

The same applies for Northern Germany where since the first excavations in the 1920s morpho-typological differences, especially in the microlith and bone point assemblages, led to a definition of an independent Early Mesolithic 'Duvensee' culture or group that was separated from the Eastern Danish Maglemose culture (Schwantes 1928; Schwabedissen 1944; Bokelmann 1971; Gramsch 1973). However, due to the close resemblance in the flint (Sørensen 2006) and bone and antler technology (David 1999; David 2009) such a strong separation seems no longer justifiable from today's perspective. Therefore, an interpretation of the North German inventories as a regional, southern expression of the Maglemosian technocomplex is widely accepted.

In sum, it can be said that the typological and chronological framework of the Preboreal Maglemosian that has been established over the last century in Southern Scandinavia and Northern Germany and to which Star Carr has contributed, must be considered trustworthy. However, this is not to say that the Preboreal Maglemosian is without chronological and typological problems. There are indeed regional variations seen both in ecology, typology and in cultural chronology across the great North European lowland during the Preboreal, as for example reflected by partly differing lithic typologies and in bone and lithic technologies. Yet despite these differences we see that there are still more which culturally unite the Preboreal assemblages of the regions, than divides. Moreover, the relative chronology, built up over years, is now gradually being confirmed and made absolute by radiocarbon dating.

In this paper we do not present all the radiocarbon dates from the sites because in general they are not comparable to those presented for Star Carr in Chapters 9 and 17: many of the dates were measured a long time ago, some using bulk charcoal, and many not using AMS dating methods or Bayesian modelling. Instead, we discuss sites which are roughly contemporary with Star Carr in terms of being Preboreal in age, dated either by pollen sequences, lithic technology or radiocarbon dating as presented in Figure 12.2. All these methods have their limitations; however, new dating programmes employing Bayesian modelling are being carried out on other sites such as Hohen Viecheln and Duvensee and it is hoped that in the future we can analyse the radiocarbon dates of many of these sites using the same methodology as employed in the recent study of Early Mesolithic British sites (Conneller et al. 2016).

\section{Site descriptions}

\section{Introduction}

There are a number of Preboreal and Early Boreal Mesolithic sites in Southern Scandinavia (Petersen 2009, 25) and these can be divided into two main categories: 'habitation sites' and 'deposition sites. Very few if any of the habitation sites have well-preserved organic materials. The deposition sites, on the other hand, are found in wetlands, often kettle holes, and thus do preserve organic remains. This dichotomy of preservation in southern Scandinavia in relation to site function can partly be explained by a lowering of the water table that took place during the Preboreal/Early Boreal period (e.g. Iversen 1967, 388). This meant that dry zones near to lakes, where habitation could take place, were not overgrown by peat during the Preboreal and in the Western Danish 


\begin{tabular}{|c|c|c|c|c|c|c|}
\hline \multirow{3}{*}{\begin{tabular}{|l} 
Sites \\
Southern Scandinavia \\
Deposition sites
\end{tabular}} & \multicolumn{2}{|c|}{$\begin{array}{c}\text { Lithic typology } \\
\text { Phases }\end{array}$} & \multicolumn{3}{|c|}{$\begin{array}{l}\text { Lithic technology } \\
\text { Groups }\end{array}$} & $\begin{array}{l}\text { Radiocarbon Dating (cal BC) } \\
1 \text { standard deviation }\end{array}$ \\
\hline & 0 & 1 & Epi A & Gr.1 & Gr.2 & , 9500, , , 9000, , , 8500, , , 80,00, \\
\hline & & & & & & \\
\hline \multirow{8}{*}{$\begin{array}{l}\text { Lundby Mose kettle hole } 6 \\
\text { Lundby Mose kettle hole } 2 \\
\text { Lundby Mose kettle hole } 1 \\
\text { Lundby Mose kettle hole } 3 \\
\text { Lundby Mose kettle hole } 5 \\
\text { Lundby Mose kettle hole } 4 \\
\text { Skottemarke } \\
\text { Favrbo } \\
\text { Vig }\end{array}$} & & & & & & \\
\hline & & & & & & \\
\hline & & & & & & \\
\hline & & & & & & \\
\hline & & & & & & \\
\hline & & & & & & \\
\hline & & & & & & \\
\hline & 0 & & & & & \\
\hline \multirow{12}{*}{$\begin{array}{l}\text { Habitation sites } \\
\text { Nørregaard VI } \\
\text { Arup context } 1 \\
\text { Arup context } 2 \\
\text { Skottemarke } \\
\text { Barmosen } 1 \\
\text { Bjergby Enge } \\
\text { Draved 611 } \\
\text { Gl Ullerød } \\
\text { Draved 604s } \\
\text { Draved 332 } \\
\text { Henninge Bostælle } \\
\text { Årup context } 3 \\
\text { Klosterlund } \\
\text { Hasbjerg } 2 \\
\text { Flaadet }\end{array}$} & & & & & & \\
\hline & 0 & & 0 & & & \\
\hline & 8 & & 0 & ? & & \\
\hline & & & & 0 & & \\
\hline & - & & & - & & \\
\hline & 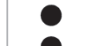 & & & ? & & \\
\hline & 8 & & & 0 & 0 & \\
\hline & & 9 & & & o & \\
\hline & & 0 & & & - & \\
\hline & & 8 & & O & - & \\
\hline & & 8 & & & 9 & \\
\hline & & 0 & & & 8 & \\
\hline \multirow{2}{*}{\multicolumn{7}{|c|}{ Germany }} \\
\hline & & & & & & \\
\hline \multirow{2}{*}{\multicolumn{7}{|c|}{$\begin{array}{l}\text { Deposition sites } \\
\text { Potsdam-Schl }\end{array}$}} \\
\hline & & & & & & \\
\hline \multicolumn{7}{|l|}{ Habitation sites } \\
\hline Pinnberg 7 & 0 & 0 & $\bullet$ & 0 & ○ & \\
\hline $\begin{array}{l}\text { Bedburg Königshoven } \\
\text { Mönchengladb. Geneicken }\end{array}$ & $?$ & & & ? & & \\
\hline Duvensee Wohnplatz 1 & 0 & 0 & & 0 & ○ & $.--a-a-0-=$ \\
\hline $\begin{array}{l}\text { Duvensee Wohnplatz } 2 \\
\text { Duvensee Wohnplatz } 8\end{array}$ & 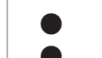 & 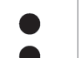 & & ? & - & \\
\hline Duvensee Wohnplatz 9 & 0 & 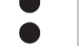 & & 0 & & \\
\hline Duvensee Wohnplatz 11 & 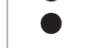 & 0 & & 0 & ○ & \\
\hline $\begin{array}{l}\text { Friesack } 4 \\
\text { Friesack } 27 a\end{array}$ & & 8 & & 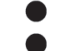 & 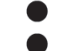 & \\
\hline $\begin{array}{l}\text { Friesack 27b } \\
\text { Hohen Viecheln }\end{array}$ & & $?$ & & 0 & 0 & \\
\hline Rothenklempenow & 0 & 0 & & 0 & 0 & \\
\hline Star Carr & & 0 & & & ○ & \\
\hline
\end{tabular}

Figure 12.2: The chronology of the Early Maglemose (Preboreal) assemblages of southern Scandinavia compared with typology, technology and absolute dating to the Star Carr assemblage. The lithic typology phase 0 is characterized by simple broad obliquely blunted microliths and large flake adzes, while phase 1 is characterized by inventories with varied obliquely blunted lanceolates and a frequency of isosceles and segment microliths and slender cores axes. The lithic technology is generally grouped on the basis of lithic blade technology. The EpiA group represents an Ahrensburgian/Long Blade Industry blade technology, the Gr.1 a simple single platform production of thick blades, and Gr.2 a production of thin blades from single fronted unipolar and dual platformed blade cores. Legend: Dots represent technologically thoroughly studied assemblages, and circles represent assemblages that need further study. The radiocarbon dating for each site is plotted from the earliest endpoint to the latest endpoint of all the calibrated radiocarbon dates from the site (at $1 \sigma)$. Dashed lines show conventional radiocarbon dates with large uncertainties. For the dating of Star Carr see Chapter 17 (Copyright Mikkel Sørensen, CC BY-NC 4.0). 
regions a more acidic geology and wetland environment exist which only seldom allows for the preservation of organic materials such as bone and antler.

In Germany the situation is slightly different in that here several habitation sites have been found with preserved faunal remains. In particular, in North-eastern Germany, sites are preserved where prehistoric people settled in wide river valleys formed by glacial meltwaters ('Urstromtäler') at the end of the last Glaciation. In these areas extensive wetlands formed which transformed into fens over time, although there were regional differences in the water table for the Early Holocene. Thus, contrary to the Southern Scandinavian material, organic artefacts at habitation sites tend to be preserved.

\section{The Preboreal bone deposits}

\section{Introduction}

There are five sites which date to the Preboreal and can be classed as bone deposition sites. Three of them have produced quantities of elk bone and the other two aurochs bone. The evidence from each of the sites clearly demonstrates that these were not natural deaths and they have typically been interpreted as either prehistoric hunting failures or deliberate ritual deposits (Pedersen and Brinch Petersen in press).

\section{Favrbo (Denmark)}

In 1920 an elk bone deposit was unearthed by peat cutting in a small bog called Krudtmosen near Favrbo on Western Zealand. The bones were excavated and examined by the geologist K. Jessen (Møhl 1980). According to Jessen the bones were found as a concentration in a lower peat layer that had been directly placed upon moraine sand. The bone material was re-analysed by U. Møhl (1980). He noted that this assemblage was represented by two individuals: an elk bull and an elk cow. Most of the bones had cut marks presumably from butchering and they had been split for marrow. The two frontal antler tines had been cut off from the bull's skull, presumably to be used for tool making. The antler and an examination of the cow's teeth suggested that the bone had been deposited in winter. Both pollen analysis and radiocarbon dating date the bones to the Middle Preboreal period (Møhl 1980).

\section{Lundby Mose kettle hole (Denmark)}

The Lundby Mose kettle hole site is situated in Southern Zealand close to the Sværdborg-Lundby bog from where numerous Maglemose sites of primarily Boreal and the Early Atlantic periods have been excavated. The kettle hole site is c. $100 \mathrm{~m} \times 40 \mathrm{~m}$ and situated on arable land. It was excavated during 1999 and 2000 by the local museum. It revealed at least nine different well-preserved bone deposits situated under the present-day water table (Jessen et al. 2015) (Figure 12.3).

Even though the bones in each of the deposits had been clearly manipulated (Leduc 2014b), not many artefacts were found that could reveal who the hunters were. In the deposit LM1 an elk antler adze, typical of the Mesolithic Preboreal (e.g. such as those from Star Carr) was unearthed, suggesting a cultural attribution to the Maglemose Culture. In deposit LM3, a lithic arrowhead had penetrated into an elk sternum, but the type of arrowhead could not be determined due to its broken base. However, the way in which the animals had been butchered and the practice of depositing elk bone are consistent with other bone deposits dating to the Preboreal period, e.g. from the sites of Skottemarke and Favrbo (Møhl 1980; Sørensen 1980).

Archaeological analysis (Hansen et al. 2004; Pedersen and Brinch Petersen in press) and zoological analysis (Leduc 2014b) of the deposits LM 1, 2, 3 and 6, revealed that one or several elk individuals had been laid into the bog as an assembled concentration of bones that had most probably been wrapped into the skin of the killed

animal. The deposit LM5 contained many more species (aurochs, red deer, pike, wild boar and dog) and the bones were more spread out. The recent interpretation of these deposits is that the single species bundle deposits (LM1-3, LM6) were laid into the lake as part of a ritual practice while the LM5 deposit represents a toss zone from a nearby site (Pedersen and Brinch Petersen in press). This site could be Lundby IV, an assemblage of material that had been surface collected close to the kettle hole before the excavation (see below, Johansson 1990). 

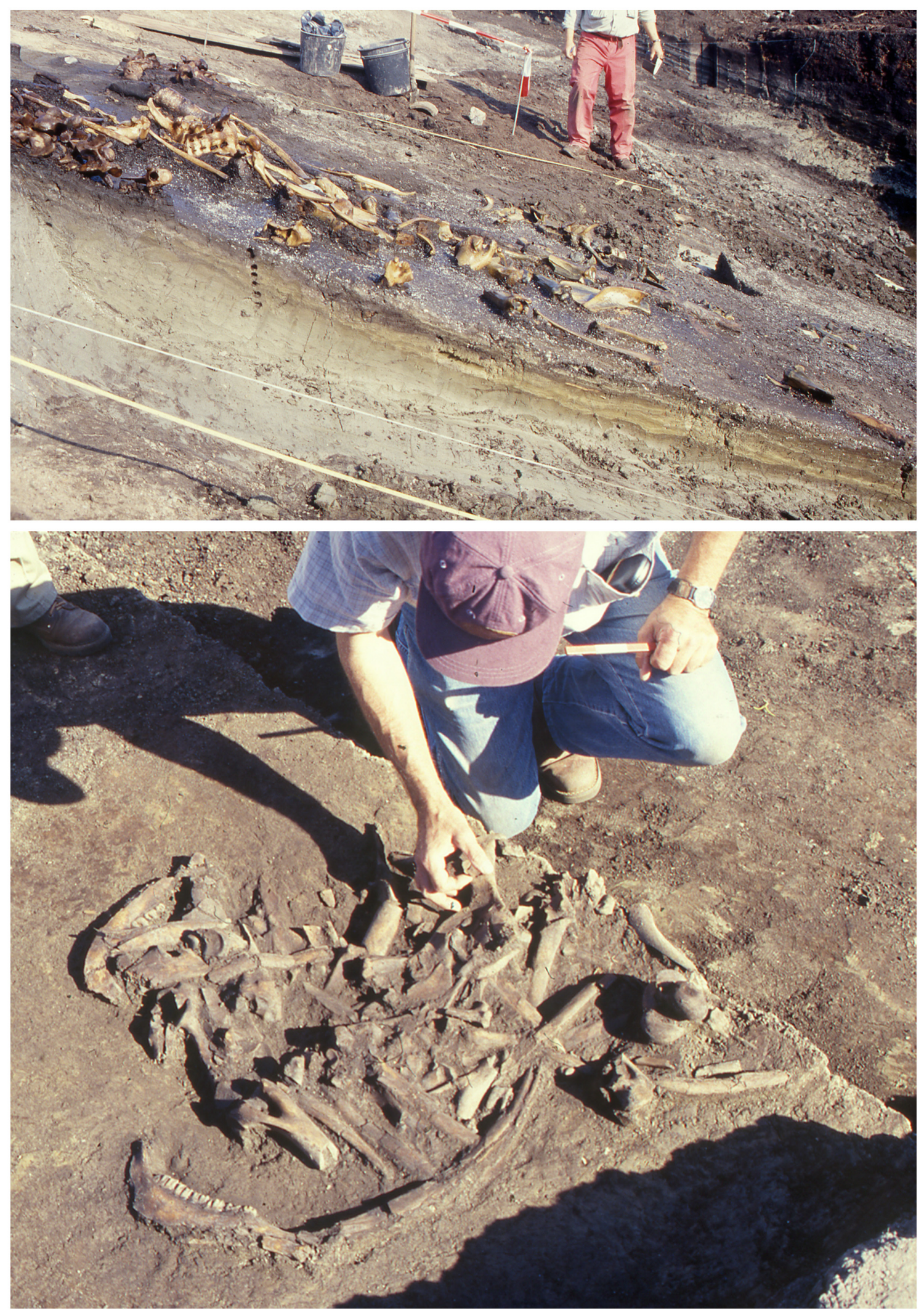

Figure 12.3: (top) The LM5 deposit under excavation with the geological profile of the layer with finds within it above the Late Glacial sand; (bottom) the LM2 deposit of bundled marrow-split elk bones (Copyright Charlie Christensen, CC BY-NC 4.0). 
The geological context of the LM1-3 and LM 6 deposits is characterized by a dark brown gyttja (organic detrital mud) directly above a Late Glacial layer of clay, suggesting an Early Preboreal date for this layer. This early date is confirmed by radiocarbon dating of the bone material, the oldest deposit being LM6 dated to the very beginning of the Preboreal period. The LM 1-3 dates are, except for the elk antler adze in LM 1, slightly younger, dating to the first half of the Preboreal, while the LM 5 layer dates to the Late Preboreal. A core taken in the kettle hole for pollen and macrofossil analysis revealed a Preboreal vegetation sequence which was supplemented by absolute ages (Jessen et al. 2015). This analysis suggests that the direct dating of the elk bones compared with the dated stratigraphy, was in some instances slightly too old (e.g. the elk antler adze from LM1). It was suggested that this difference might represent a hard water effect due to elks living in an aquatic environment and consuming water plants. The dating of these bone deposits represents the earliest Mesolithic activity, including tool making in Northern Europe, yet there are no dates for habitation sites that can further support the presence of people within Southern Scandinavia during this early phase.

\section{Skottemarke (Denmark)}

This bone deposit was found in 1902 during peat cutting in a bog in the central part of the island of Lolland. S. Müller and G. Rosenberg from the National Museum undertook an excavation of the find spot and recovered in situ contexts. The bones were re-analysed by U. Møhl in 1978 at the Danish zoological museum in Copenhagen and were interpreted as being the remains of at least six elk (one calf, four cows and a bull) (Møhl 1980). Most of the bones had been split for marrow but metapodials were missing, possibly because they had been selected for tool production. Based upon the age of the elk calf bones it was deduced that these were killed during winter. No tools were found within the bone deposit; however, a concentration of finely barbed bone points and flint artefacts were found only a few metres away but clearly separated from the bones. Pollen sampled from around the finds and a column, taken during the original excavation and sent to the geological museum in 1902, revealed that the contexts with the finds in them were of Middle Preboreal date (Sørensen 1980). This was confirmed by radiocarbon dating of the elk bones (Møhl 1980). The evidence shows that after the animal was killed, each of the shoulder blades were stabbed from the inside out leaving a large hole in each of them; because of this, the Skottemarke bone deposit is interpreted as a ritual deposit that can compared to historical ritual Saami practices (Møhl 1980; Pedersen and Brinch Petersen in press).

\section{Potsdam-Schlaatz (Germany)}

In 1984, during building work of a new residential area in Potsdam, the partial remains of a male aurochs skeleton were found. These remains included the skull, the majority of the spine, and some ribs. It is thought to have died in a shallow river bed, probably during the summer or autumn (Gustavs 1987, 32-34; Weiße 1987, 61). Cut marks were evident on the bones and undiagnostic stone tools were found in association with it. As the missing bones relate to the meat-bearing parts of the carcass it is thought that these parts must have been transported to the campsite (Gramsch 1987b, 50). Other bones were also found at the site: single bones of another aurochs, red deer, horse and wild boar. The sedimentological and pollen evidence suggested a date belonging to the Younger Dryas (Loch Lomond Stadial in the UK, see Chapter 4) (Gustavs 1987; Kloss 1987; Weiße 1987). However, because this fauna was more likely to be associated with the Early Holocene, Kloss $(1987,65)$ suggested a younger date. The aurochs and associated fauna were radiocarbon dated, placing the finds into the Early Preboreal (Benecke et al. 2002), which still predates the large Mesolithic habitation sites such as Friesack, Hohen Viecheln or Duvensee. It is therefore difficult to provide any further interpretations, particularly due to the lack of diagnostic stone tools.

\section{$\operatorname{Vig}($ Denmark)}

The aurochs from Vig was found by a local farmer in a small peat bog in Northwestern Zealand during May 1905. He reported the find to the Zoological Museum and geologist and botanist N. Hartz went to examine it: the skeleton was almost complete and extremely well preserved and three broad, simple obliquely blunted 
points were found with it. A zooarchaeological examination showed healed and fresh wounds with two flint points embedded into the bone. From this, it was hypothesised that the aurochs had been hunted several times by people hunting with bows and arrows and that it died within the lake from its severe wounds. The microliths are typical of the earliest Maglemosian phase (Phase 0). They were made from broad irregular blades which are typical of the first blade technology group (Group 1). Hartz also examined the stratigraphy and demonstrated that the aurochs was unearthed from the bottom of a brown gyttja layer and just above a sand layer. The appearance of aspen (Popular tremula) and pine trees (Pinus sylvestris) provided a Middle Preboreal date and an AMS radiocarbon date on a bone sample has since confirmed this (Fischer 1996).

\section{The habitation sites}

\section{Introduction}

Fourteen habitation sites dating to the Preboreal are discussed here, ordered alphabetically. They produce a variety of information though as can be seen, very little in the way of organic material. Therefore, dating is usually carried out using typological and technological analysis of the lithics and where radiocarbon dating is possible it is generally carried out on charcoal.

\section{Årup context 1 (Sweden)}

The Årup site complex is situated in Northeast Scania where the large lakes of the region run out into the Baltic Sea through the River Skrabeåen. The excavations were carried out by the Swedish Heritage board prior to a road construction (Karsten and Nilsson 2006). In total, nine clearly separated concentrations of lithics and, in some cases, structures were investigated of which three can be defined as belonging to the Preboreal Mesolithic of Southern Scandinavia. In this area the subsoil is sandy, meaning there is little possibility for organic preservation.

The oldest of the Årup concentrations is context 1 , which was found $1.5 \mathrm{~m}$ below a sandy soil deposited by Baltic Sea transgressions. This context consists of a $5 \times 5 \mathrm{~m}$ concentration of 2118 lithics. The majority of the lithic material was of the local Kristianstad flint, but importantly, 267 pieces of Maastrichtien flint must have been imported to the site, most probably from Western Scania or from Zealand, where these sources appear. The assemblage almost only represents blade production and it has a limited tool inventory consisting of 25 microliths, 10 microburins, 10 end scrapers, three knives with retouch, three burins, burin spalls and a hammer stone. No adze production was found in the material. Thorough investigations were carried out using spatial analysis, refitting of the lithics and use wear analysis. From this, the find spot was interpreted as a single event, most probably a short-term hunting and butchery camp.

The microliths are generally simple obliquely blunted points, yet some have more retouch along the lateral edge. The blade industry represents an Ahrensburgian tradition where large thin blades are detached from flat single fronted cores by means of a soft stone hammer. The find layer could not be dated, but the overlaying layer in the well-developed geological stratigraphy has been dated by charcoal (from pine) and corresponds to the Middle Preboreal period, meaning that context 1 is older than this period (Karsten and Nilsson 2006, 61).

\section{Årup context 2 (Sweden)}

Årup context 2 is represented by a c. $15 \times 7$ m concentration of 3984 lithic pieces (Karsten and Nilsson 2006, 86). The lithic material was situated in a layer that was c. $0.3 \mathrm{~m}$ thick, implying that some bioturbation had affected the site. Several large boulders were found within the excavation area, one of which had clearly been employed as a seat and used for flintknapping. Three possible postholes were found in relation with the lithic concentration and interpreted as part of a hut or windshield construction.

The material is characterized by a relatively small sized blade industry and tool production. In all, 10 microliths, 7 microburins, 11 endscrapers, 4 borers, 2 knives and a flake adze were identified. Approximately one third of the lithic material was burned. Only 104 pieces of flint were imported Maastrichtien flint whilst the 
remainder was local Kristianstad flint. Spatial analysis, refitting and use wear analyses were carried out and showed that there had been a living area with three fireplaces, an area of habitation and three activity areas in which butchering, flintknapping and bone antler working had taken place.

The microliths are obliquely blunted points, but some have an extended lateral retouch. One microlith is of the isosceles triangle type. The blade production method is characterized by use of single platform circular cores and hard hammer technique, as seen within the Barmosen 1 assemblage (below). This typology and technology is typical of the Middle Preboreal period in Southern Scandinavia (Sørensen 2006). A charcoal sample of pine was radiocarbon dated to the same period (Karsten and Nilsson 2006:103).

\section{Årup context 3 (Sweden)}

At Årup 3 only 129 lithic artefacts made from the local kristianstad flint were found (Karsten and Nilsson 2006). In all, two microliths of the simple lanceolate type, a borer, a burin and two flake adzes, a strike-a-light and a hammerstone were identified. Twenty-nine pieces were defined as irregular blades and five pieces were identified as used blade cores. The site is remarkable because of a very well-preserved fireplace and what is thought to be four postholes and features which may represent part of a wall construction. This has been interpreted as a hut construction with an outside hearth. Due to the small number of artefacts, the site can only be tentatively typologically dated to Maglemosian phase 1 and technogroup 2. A radiocarbon date on pine charcoal from the fireplace provided a date for the Latest Preboreal period (see Figure 12.2).

\section{Barmosen I (Denmark)}

The Barmosen I site is located in the Barmosen bog in Southern Zealand just south of the large Sværdborg/ Lundby bogs. It was excavated in 1967 and published in 1990 by the excavator A. D. Johansson. A cultural layer with a central concentration of lithic artefacts was found at the bottom of a turf layer just above gyttja, indicating that the site was originally in a wetland position close to a former lake. In total, $99.25 \mathrm{~m}^{2}$ were excavated in $1 / 4 \mathrm{~m}^{2}$ and 3-dimensional plotting of tools was undertaken.

A large bark layer was encountered which was almost the same size as the lithic concentration and was interpreted as the floor of a hut construction. Above this lay a sand and charcoal layer which was $2.4 \times 1.5 \mathrm{~m}$ wide, up to $70 \mathrm{~mm}$ thick. This was interpreted as part of a fireplace construction. The spatial distribution of the lithic material revealed a circular c. $6 \times 6 \mathrm{~m}$ shape with a bimodal concentration in its centre. An analysis of the weight of the lithic material showed that the larger flint is distributed on the periphery of the concentration, along with what could have been a wall towards the east and west, whilst the very small pieces of flint revealed activity areas inside the construction. Moreover, the small flint distribution partly continued towards the north and south from the concentration leading to the interpretation that these areas might have functioned as entrances to a hut construction. In the central sand layer fish bones and bird bones were excavated e.g., pike (Esox lucius), carp (Cyprinidae) and grebe (Podiceps). From the gyttja layer beneath the sand layer an aurochs bone was excavated.

In all 1353 artefacts were classified as lithic tools, 19,295 pieces as lithic debris of different types, five pieces as hammerstones, 14 pieces as bone tools and 87 fragments of seemingly not worked bone, antler and tooth. Moreover, 22 lumps of pitch/resin, two of which had human teeth imprints, were recovered. The tool inventory is dominated by broad obliquely blunted points $(n=68)$, burins $(n=68)$, endscrapers $(n=65)$, symmetrical flake adzes $(n=34)$, drills $(n=24)$ and one core axe. Moreover, many differently retouched pieces, which cannot be classified into formal tool type categories, were recorded. From analysing the lithic debris it was shown that lithic production was carried out at the site, except that large blanks for flake adzes were serially produced at other locations and imported to the site.

The lithic technology at the site can be characterized as a blade and a flake adze industry. Irregular blades of various sizes were serially produced from single platform or multi-platform cores by hard hammer technique (Sørensen 2001; Sørensen 2006). From these, the majority of the tool types were produced (scrapers, burins, drills, knives etc). The flake adze production was performed from large serially produced blanks, a method that has been identified at Early Mesolithic sites specifically in the Barmosen area (Johansson 1990; Sørensen 2006). Their production into adzes can be identified by diagnostic 'wing shaped' flakes also found at Barmosen I. The bone tool inventory was rather fragmented and affected by burning. Among the 
fragments was part of a finely serrated bone point of Early Mesolithic type. Several other fragments had burin facets and grooves and must be interpreted as production waste or preforms of a bone industry conducted at the site.

The tree species were ascertained from 595 pieces of charcoal from the cultural sand layer. The majority of these were from poplar (Populus sp. $53.4 \%$ ), but birch (Betula sp. 20\%) and pine (Pinus sp. 10\%) were also present (16.6\% was defined as either poplar or willow (Salix sp.)). It was concluded that the range of species represented a Middle Preboreal forest regime. AMS dating of the charcoal placed the site into the Early/ Middle 9th millennium cal BC (Fischer 1996). When typologically and technologically compared to the sites from Duvensee (e.g. Duvensee 8) and to the microliths of the Vig aurochs and the respective radiocarbon dates of these sites, the radiocarbon dating of the Barmosen site appears to be too young. The reason for this is unknown, although it has been suggested that humic acid contamination from the peat above the cultural layer may have influenced the radiocarbon dates, despite a pre-treatment of the samples.

\section{Bjergby Enge (Denmark)}

The Bjergby Enge site was found within a peat bog in Western Zealand in 1952. This was found as a surface scatter of very homogeneous lithic material on the surface of the harrowed peat bog in an area of c. $7 \times 7 \mathrm{~m}$ and was collected by a local amateur. Later the area was excavated by another amateur. No preserved organic artefacts can be associated with the assemblage. The material was briefly published by the archaeologist $\mathrm{K}$. Andersen (1982). The finds include c. 1200 pieces of flint and blade production is represented by c. 330 pieces and 15 cores. In total, 52 broad obliquely blunted points, 2 knives, 2 drills, 5 end scrapers and a flake adze are present in the assemblage. Due to its typology and simple blade production, the site is defined as belonging to the Earliest Maglemose Culture with a close affinity to the Barmosen 1 assemblage.

\section{Draved (Denmark)}

A cluster of Early Mesolithic sites are located in the Draved bog in Southwestern Jutland. Around 30 find spots with a Mesolithic inventory are known from the bog, four of which were excavated by H. Kapel of The National Museum of Denmark between 1959 and 1970 (Sobotta 1991). The excavated sites are represented by Draved 611, 604, 329 and 322; Draved 604 is further separated into two sites 604 and 604 South (S). There is not much information available about the actual excavations except that the sites were excavated in metre squares and the stratigraphy was described as a sandy soil with possible finds in its top layer, overlain by peat, and with no preservation of organic material in the find layers except for charcoal. Sieving of the excavated soil was not undertaken.

In all cases the sites are represented by concentrations of lithic artefacts, typically c. $5 \times 7 \mathrm{~m}$ in size. These clusters have been spatially analysed and compared to other sites of the Maglemose culture by Sobotta (1991). The sites have been relatively dated by their microlithic typologies as well as being dated by radiocarbon analysis; however, the radiocarbon dates are not secure. Based on typology the oldest site is 611 due to the presence of broad obliquely blunted points as the only type of lithic point. This site is dated by radiocarbon dating to the Middle Preboreal period. Site 322 includes simple obliquely blunted points but also microliths with fully retouched lateral edges. Moreover, the microliths were generally made on thin, long and narrower blades. For these reasons this assemblage can be considered slightly younger than assemblage 611 . The radiocarbon dating of this site consisted of two dates; one falls into the Late Preboreal period and one into the Early Boreal period. Sites 604 and $604 \mathrm{~S}$ include a combination of obliquely blunted points and isosceles triangles. This is a typical composition for sites dated to phase 1 corresponding to the Late Preboreal or the Boreal transition. Site 329 is dated typologically and by radiocarbon dating to the Younger Boreal period.

\section{Flaadet (Denmark)}

The Flaadet site is situated on the island of Langeland. It was excavated during the spring of 1973 by Langelands Museum. The geology and the vegetation history in relation to the site was analysed by researchers from The National Museum (Fredskild 1975; Skaarup 1979). The Flaadet site is located on a former small island centrally placed within less than $1 \mathrm{~km}^{2}$ of a drained bog. The bog was ploughed during the mid 20th century and the site 
appeared as a flint scatter. The excavation of the site revealed that the lithic material was generally situated in the plough soil consisting of heavily degraded peat including chalk from the former lake bottom. The pollen analysis of the lake stratigraphy suggested that the peat had built up from the Late Boreal and that the island had been inhabited before this, during a lowering of the water table from the Late Preboreal to the Boreal periods (Iversen 1967).

The excavation revealed a concentration of typologically consistent lithic material within an area of c. $17 \times$ $13 \mathrm{~m}$. This concentration was completely excavated and recorded by metre square. Test excavations and field surveys revealed that no other lithic concentrations could be found on the island or within the nearby bog. In total, 26,212 lithic artefacts were classified and of these 2064 pieces were identified as tools. A very small assemblage of bones was recovered in the soil within the excavated site area and wild boar, red deer, roe deer and possibly elk were identified.

Due to its size and stratigraphy the site was interpreted as a palimpsest; however, it is a very concentrated spatial distribution with consistent lithic typology that suggests the site was formed within a short or modest period of time. The site occupation phase must correspond to a period when the lowering of the groundwater made it possible to inhabit the island, i.e. during the Late Preboreal or Early Boreal periods.

The site is of archaeological importance due to its consistent lithic material, thus making it a key typological site of this particular phase. The blade industry is characterised as consisting of irregular thin blades produced from single or dual platform cores using what is considered to be a direct, soft stone hammer technique. In total, more than 400 microliths were recorded. The vast majority of these are narrow obliquely blunted points with one partially or fully retouched lateral edge $(\mathrm{n}=293)$; however, triangular microliths (isosceles) appears as a clear component $(\mathrm{n}=53)$ as well as segment shaped microliths $(\mathrm{n}=18)$. Other tools were generally made on blades and are classified as end scrapers, simple burins, borers and a variety of differently retouched blades. Axes/adzes appear as slender wellformed core axes and only a minority of irregular flake adzes appear. Typologically the site is dated within phase 1 and technologically within group 2, corresponding to the Late Preboreal or Early Boreal periods (Figure 12.2).

\section{Gl. Ullerød (Denmark)}

The site of Gl. Ullerød is located in Northeast Zealand within a drained river and lake system. It was excavated in 2001 by archaeologists of the local Hørsholm Egn Museum after it was discovered during a modern reconstruction of the river (Jensen 2002). The site was excavated in square metres and the soil was wet-sieved. The excavation revealed a distinct half circular cultural layer, c. $10 \mathrm{~m}$ wide, containing sand, charcoal, burnt stone and flint artefacts. Further, it was determined that only about half of the site was preserved as the cultural layer was cut through by a machine digger. The analysis of the remaining cultural layer demonstrated a clear central concentration of artefacts. Furthermore, the cultural layer contained two central sand and charcoal areas, interpreted as fireplaces. The finds inventory is modest and consists of c. 500 small blades, 13 microliths, 12 microburins, 11 blade knives, 3 end scrapers, 2 burins and a single adze made from a large frost fracture. The microliths are all simple obliquely blunted points but were made on thin and narrow blades. The site is therefore considered typologically and chronologically related to the Klosterlund assemblage, dated to the Late Preboreal Maglemose Culture. Unfortunately, the site did not yield any organic remains and reliable dating of charcoal from the fireplaces has not been achieved.

\section{Hasbjerg II (Denmark)}

The Hasbjerg II site was found in the Sværdborg bog, South Zealand by archaeologist A. D. Johansson in 1965 (Johansson 1990, 54ff). It was located in a drained and ploughed bog, very near to a promontory reaching out into the former bog. In 1968 Johansson decided to excavate the plough soil in metre squares and it was found that the site stretched out as a concentration of lithic artefacts with very limited in situ preservation. In total, $58 \mathrm{~m}^{2}$ were excavated showing a clear concentration in the middle part of the excavated area. The following analysis of the burnt flint revealed that the material was centrally concentrated, suggesting a central hearth. In total, 8058 flint pieces were recovered. A total of 83 microliths were found; 50 of which were simple obliquely blunted points, nine had some extended lateral retouch and 12 were defined as isosceles types, the rest as fragments. Of the other tools, 19 were end scrapers, four borers, 38 burins, 22 blades with lateral retouch, 15 flake adzes and two core axes. The blade cores and the blade material reveal a single and dual platform blade production method by means of soft hammerstone percussion (Sørensen 2006). No organic artefacts were found and consequently no absolute dating was possible. From seriation analysis of the microliths the Hasbjerg II site is 
demonstrated to be closely related to the Klosterlund, the Flaadet and the Star Carr assemblages (Johansson 1990, 52), an interpretation that can be confirmed by a comparison of the blade production methods. The dating of the site is therefore typologically dated to the Maglemose culture phase 1 and techno group 2, corresponding to a Late Preboreal date.

Henninge Boställe (Sweden)

The Henninge Boställe site is situated in Central Scania on a small promontory on the north side of a river that, during the Mesolithic, connected Lake Ageröd with the western Ringsjön. The site was discovered during the middle of the 20th century by amateur excavators. It was then excavated by the archaeologist C-A. Althin. The excavation was only very briefly described (Althin 1954), yet it was stated that some undisturbed parts of a settlement layer were preserved. Based on Althin's site description, it can be assumed that the site was not completely excavated. In total, c. 3649 lithic artefacts were retrieved during the excavation. Nineteen microliths were defined as simple obliquely blunted points and isosceles triangles. Moreover, five core axes, three borers, 26 end scrapers, 36 burins and four blade knives were recovered. The blade and core material revealed a blade production method from single platform circular cores by means of hard hammer percussion. No organic preservation was mentioned and therefore there are no absolute dates. Due to the types of microliths and the 'crude' blade industry, Althin interpreted the assemblage as belonging to his Oldest Mesolithic phase, i.e. the Preboreal period.

\section{Klosterlund (Denmark)}

The Klosterlund site is located in Central Jutland on a small sandy promontory stretching out into the Bølling bog, a former lake that has now been restored. Its excavation was undertaken in 1936, led by T. Mathiassen and with participation of the botanists J. Iversen and J. Troels-Smith (Mathiassen 1937). A total of $194 \mathrm{~m}^{2}$ were excavated in a $10 \mathrm{~m}$ trench located between the promontory and the bog. The cultural layer consisted of dark sandy soils with charcoal and lithic artefacts. It was between 0.1 and $0.4 \mathrm{~m}$ thick and located directly on a sandy subsoil and overlain by peat. The acidic subsoil did not yield any bone or antler artefacts. In total, c. 30,000 lithic artefacts were excavated. Of these, 1298 were classified as tools by E. Brinch Petersen (Petersen 1966).

The typology of the majority of finds includes simple narrow obliquely blunted points, some with fully retouched lateral edges and a few segment microliths. Small narrow core axes and irregular flake adzes made on frost fractured blanks were also present. The typology corresponds to Phase 0 , thus dating to the Preboreal. The blade industry was characterized by thin irregular blades produced from single fronted, often dual platform, blade cores by means of the soft stone hammer technique (Sørensen 2006). This blade production method and concept is typical of the second technological group in the Maglemosian, dated to the Late Preboreal and Boreal periods. Geological dating of the stratigraphy and the cultural layer places the site in the Late Preboreal period (Iversen 1967). Four conventional radiocarbon results have been made on charcoal which dates the cultural layer to the late 9th millennium cal BC. The relatively northern location in Central Jutland of Klosterlund suggests that the vegetation was Preboreal later, as also demonstrated by its radiocarbon dating, than in for example Northern Germany. Overall, the Klosterlund site can be defined as a palimpsest of occupations that was only partly excavated. However, the consistent typology of the assemblage as well as the stratigraphy in which the cultural layer is clearly apparent beneath the peat layers suggests that the site was only inhabited during a Preboreal vegetational phase.

\section{Lundby IV (Denmark)}

The Lundby IV site is located in Southern Zealand only a few hundred metres from the Lundby Mose kettle hole. At this site a concentration of lithic artefacts on the surface of the bog were found in 1965 by the local archaeologist Axel Degn Johansson. In addition, a few artefacts made from bone and antler of typical Early Mesolithic types, such as fragments of a finely serrated bone point, were also found. The flints from this concentration have a very distinct white patina that was very different to other stray finds found in the same area. In total, 15 microliths were found, 14 of which were simple obliquely blunted points, and one isosceles triangle.

Due to the microlith inventory and the appearance of large flake adzes the site is defined as a 'Barmosen' type site and can be relatively dated to the Middle-Late Preboreal period. It can be assumed that the people living at the Lundby IV site were responsible for one or more deposits in the Lundby kettle hole (see above). Due to 
the affinity with the Barmosen 1 assemblage, it is likely that the Lundby IV site was in use during the Middle Preboreal period and thus may be related to the LM5 deposit in the Lundby kettle hole.

\section{Nørregaard VI (Denmark)}

Probably the clearest Early Mesolithic site in Southern Scandinavia is Nørregaard VI which is located in central Southern Jutland. The site was excavated in 1994 by archaeologists from the local museum prior to the construction of a highway. The site is relatively high above sea level and is not found within a wetland situation. In all, 3184 lithic artefacts were recorded, of which 217 were classified as tool types: microliths $(\mathrm{n}=18)$, axes/ adzes $(n=20)$, end scrapers $(n=10)$, burins $(n=56)$ and borers $(n=2)$. The material was excavated from both the plough soil layer and the sandy subsoil below and recorded in $1 / 4$ metre squares. The spatial distribution of the artefact material reveals a dense concentration c. $6 \times 6 \mathrm{~m}$ in diameter and the existence of a central hearth has been suggested through the examination of the burnt lithic debitage (Figure 12.4). The site has been interpreted as a short-lived habitation site, including a possible hut/tent structure (Sørensen and Sternke 2004).

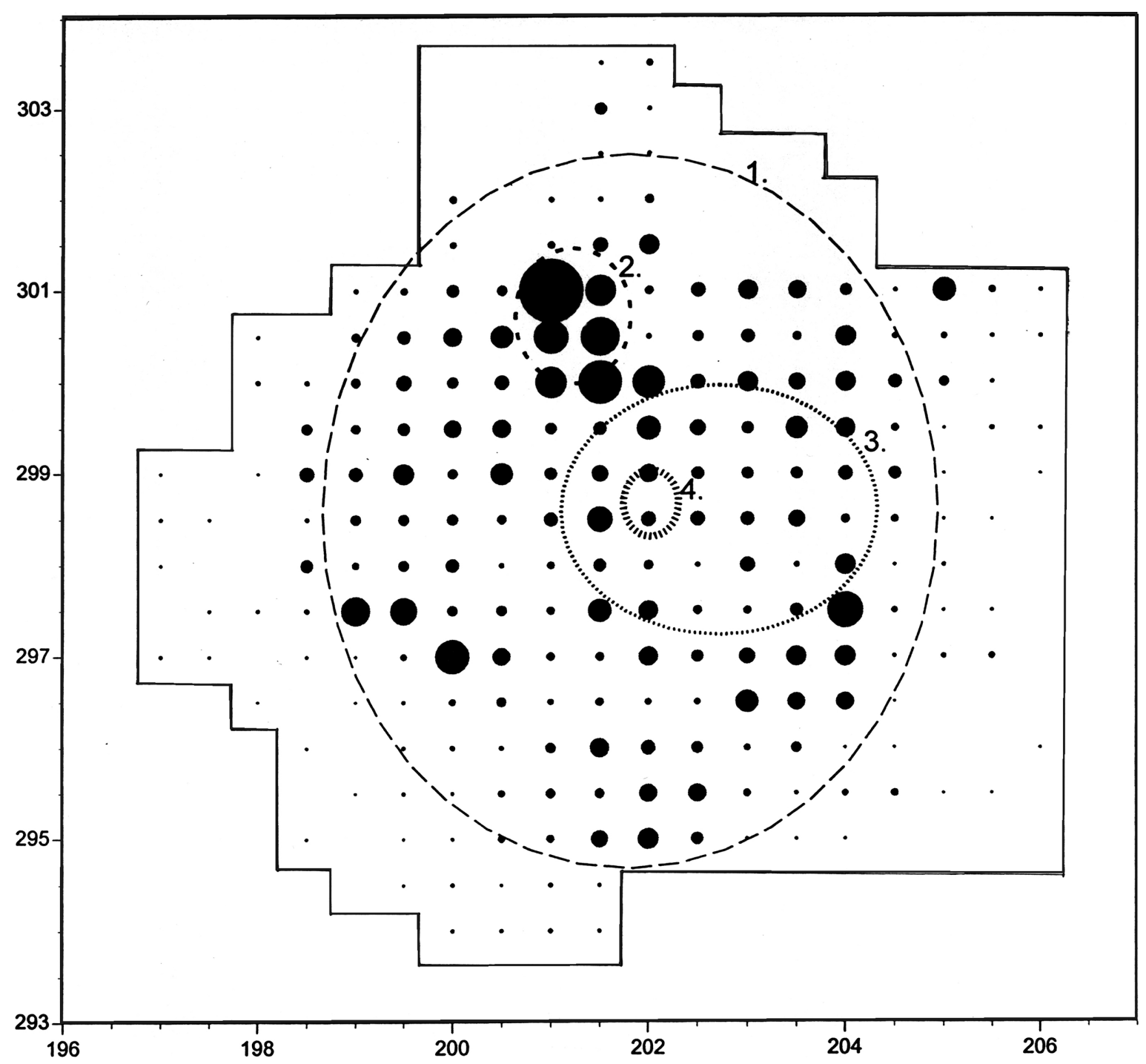

Figure 12.4: The spatial interpretation of the Nørregård VI site. Concentration of lithic artefacts recorded below plough soil in $1 / 4 \mathrm{~m}^{2} .1$. Knapping and lithic tool activity area; 2 . main knapping area; 3. habitation area; 4. main hearth (after Sørensen and Sternke 2004. Copyright Mikkel Sørensen, CC BY-NC 4.0). 
The assemblage includes simple microliths typical of both the Early Maglemosian and the Epi-Ahrensburgian as some of these have basal retouch making them similar to zonhoven points (Figure 12.5) (Taute 1968). The main reason that the site is considered to be transitional Mesolithic is the production of flint adzes made from large frost fractured blanks. In total, four flake adzes (and eight preforms/fragments) and two narrow core axes (and four preforms/fragments) are present. This axe/adze typology of large flake adzes and slender core axes and their technological productions are typical of the Preboreal Maglemose culture as seen at the Barmosen and Draved sites (see below). However, the blade industry and the appearance of imported long blades, some of which were clearly bruised, point to the Epi-Ahrensburgian/long blade complex. It should be stressed that due to the limited spatial distribution, the modest number of artefacts and the consistent lithic technology and typology, the Nørregård VI assemblage cannot be interpreted as a palimpsest or a chronologically mixed site. Unfortunately radiocarbon dating cannot be carried out due to lack of organic preservation; however, the adzes indirectly date the assemblage and the site to a landscape with trees, i.e. the Preboreal period.

\section{Pinnberg 7 (Germany)}

The Ahrensburg Tunnel valley is renowned for the unique and vast sites of Stellmoor and Meiendorf excavated by Alfred Rust and dating from the end of the Younger Dryas or the Earliest Preboreal periods. However, this area was also occupied in slightly later times, e.g. the site of Ahrensburg-Pinnberg 7 (Rust 1958a). At this site,
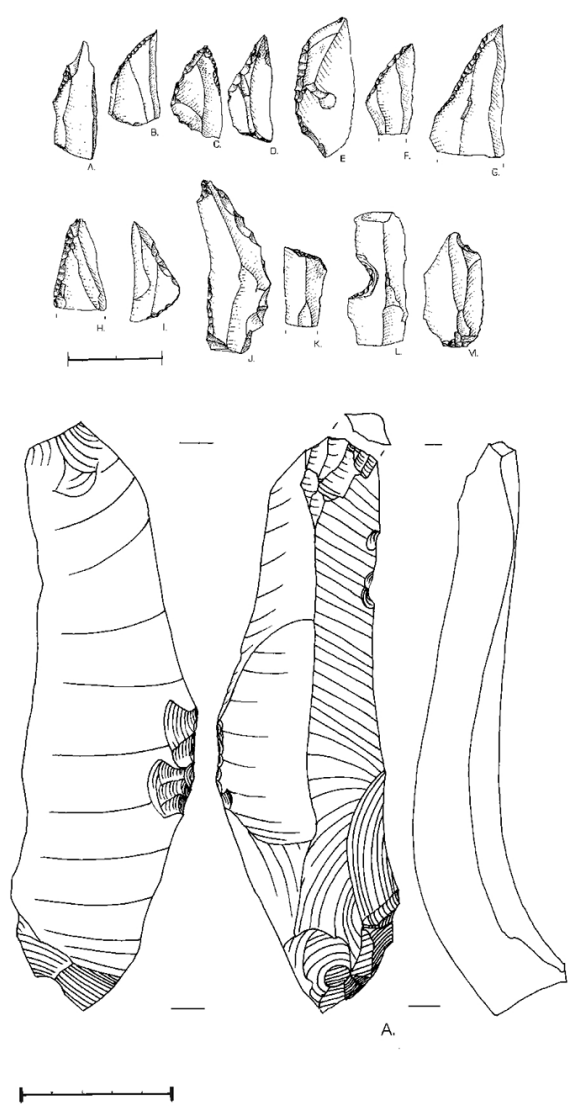
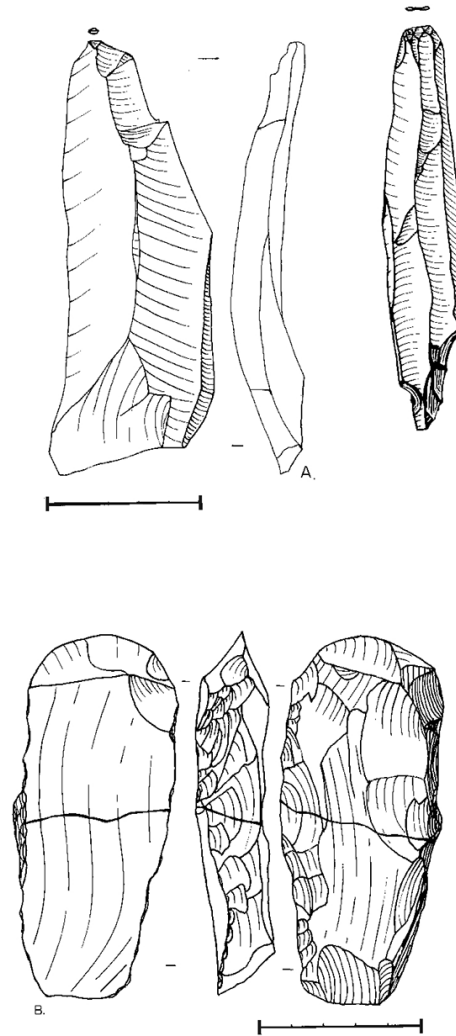

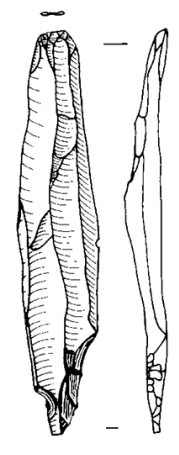

B.
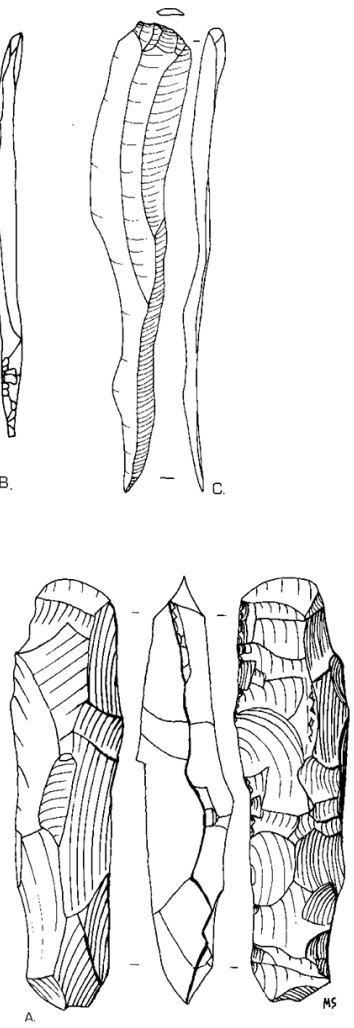

Figure 12.5: Lithic artefacts from Nørregaard VI. (Upper left) microliths and preforms (scale $20 \mathrm{~mm}$ ); (upper right) large blades (scale $50 \mathrm{~mm}$ ); (lower left) long blade with bruised edges (scale $50 \mathrm{~mm}$ ); (lower right) large flake adze and slender core axe (scale $50 \mathrm{~mm}$ ) (after Sørensen and Sternke 2004. Copyright Mikkel Sørensen, CC BY-NC 4.0). 
Rust uncovered an extensive artefact inventory dating from the Late Palaeolithic to the Late Neolithic or Early Bronze Age. Originally aiming to find huts of the Late Glacial reindeer hunters, he almost completely excavated the prehistoric settlement area. Due to the artefacts it was long assumed that Pinnberg 7 could provide information on the transition between the Late Palaeolithic and Early Mesolithic technocomplexes. This was even more likely as Rust separated up to nine different occupation layers from which one was dated slightly older than the sites in Mullerup and Duvensee, i.e. the Maglemose Culture (Rust 1958b, 32-55, 76). Consequently, Rust defined a cultural entity which he entitled the 'Pinnberg-Kultur'. He also discovered six huts and three graves. Due to the extraordinary character of the site it received a lot of attention when it was finally published in 1958, but doubts on the chronological distinctness of the different cultural layers were raised shortly after (e.g. Gramsch 1960, 63; Taute 1968, 214; Bokelmann 1971, 26). A recent re-evaluation of the archive material could not verify the existence of the hut and grave features (Groß et al. 2016; Groß et al. in press a). Furthermore, a technological re-analysis of the blades from Pinnberg 7 could not find any indications that the proposed occupation layers can be comprehensibly retraced, even though clearly different striking techniques were proven. As a result, Groß et al. (in press a) concluded that Pinnberg 7 'has to be regarded as a mixed find inventory that represents a wide chronological range' and that Rust's chronologically different occupation layers cannot be proven (Figure 12.6).

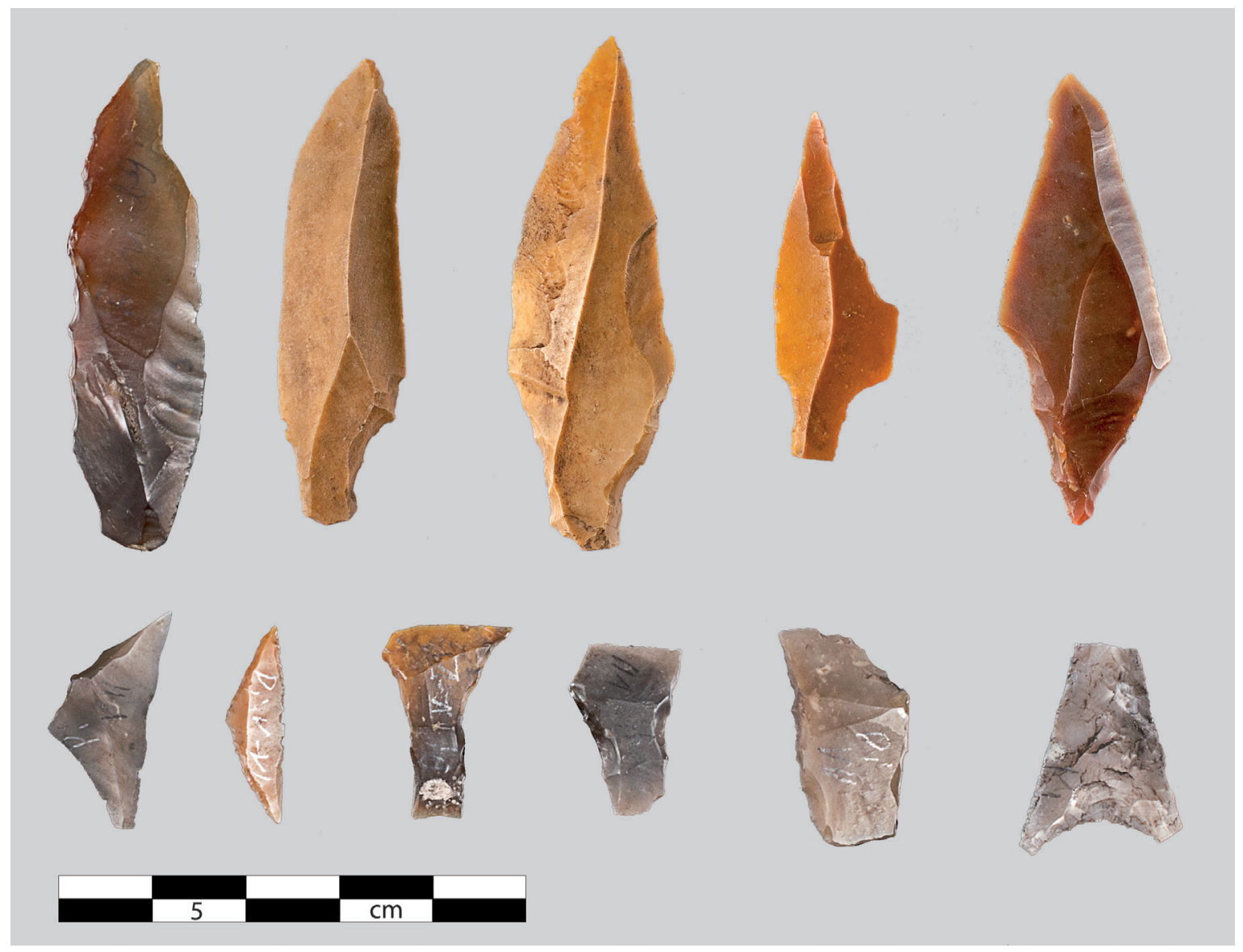

Figure 12.6: The wide chronological span of the finds from Pinnberg 7 is also reflected by the lithic projectiles. (Top row) backed point and four tanged points from the Late Palaeolithic; (lower row) a simple point (chronologically indeterminate), one triangle microlith from the Early Mesolithic, three transverse arrowheads from the Mesolithic/Neolithic transition and a surface retouched arrow head from the Late Neolithic or Early Bronze Age (Photograph by Claudia Janke. Copyright Archaeological State Museum, CC BY-NC 4.0). 


\title{
Settlement sites with organic preservation
}

\author{
Introduction
}

There are only six Preboreal sites, classified as settlement sites with organic preservation, all of which have been found in Germany. The organic remains provide the potential for better dating but also provide a suite of artefacts and ecofacts which expand our understanding of the material culture and how people subsisted during this period. There are also some striking similarities with Star Carr, particularly the antler frontlets found at Bedburg-Königshoven and Hohen Viecheln.

\section{Bedburg-Königshoven \& Mönchengladbach-Geneicken (Germany)}

In 1987 the site Bedburg-Königshoven was excavated by Jürgen Thissen. The site was dug as a rescue excavation in advance of opencast lignite mining and consequently was destroyed. Located c. $20 \mathrm{~km}$ south-east of Mönchengladbach in the Rhineland, the site has become known for two antler frontlets found in the former shore area of an ancient oxbow lake (Figure 12.7) (Street 1989, 9-11; Street 1998, 165; Wild in press). Several other bones from different animals were found here, as well as Early Mesolithic artefacts made from stone and bone. The remains of aurochs are by far the most numerous at the site (Street 1999). Cut marks on many bones provide evidence for butchery but there is also evidence for domestic activities. The site is dated to the Early Preboreal (Street et al. 1994).

Other evidence for the exploitation of aurochs is provided by the site of Mönchengladbach-Geneicken. Here in 2014, aurochs remains were found in an area of $25 \mathrm{~m}^{2}$. Almost $80 \%$ of the skeleton is represented and it could be shown that the meat and marrow-rich parts must have been cut and then thrown back into the shore area where the carcass was located (Heinen 2014, 300-301). Two microliths were found in association with the bones so that it is likely that these are projectiles from the hunt, especially because they show impact damage. Two concentrations of Mesolithic finds were found in the direct vicinity but a connection between the three finds spots is not yet proven (Richter et al. 2015, 474).

\section{Duvensee (Germany)}

The Duvensee peat bog in south-west Schleswig-Holstein, Northern Germany, represents one of the most prominent Stone Age palaeo-landscapes in Northern Europe. After the first archaeological investigations of Mesolithic sites by G. Schwantes and K. Gripp in the 1920s, and later by H. Schwabedissen, further research was conducted by Klaus Bokelmann from the 1960s. An intensive survey and excavation programme led to the discovery of several new Mesolithic and Neolithic camp sites on small islands or peninsulas on the western border of the former lake. Currently, 24 find spots in the bog area are known, despite several Stone Age sites having been destroyed by ploughing on the sandy-loamy shore areas of the Duvensee lake (Figure 12.8). The Preboreal sites Wohnplatz 8 and 9 and the Early Boreal sites Wohnplatz 1, 2 and 11 are of particular interest for the present study. The outstanding preservation of these campsites with hearths, bark mats and flint knapping areas allows detailed examinations of the spatial organisation of prehistoric hunter-gatherer campsites, even though they may present only one very specialised and temporary part of the economic and settlement behaviour.

The oldest Mesolithic sites known so far in the Duvensee bog are Wohnplatz 8 and 9, which are situated close to one another on a small former island at the western border of the former lake. Wohnplatz 8 was excavated by Bokelmann between 1978 and 1981 (Bokelmann et al. 1981), whereas Wohnplatz 9 was investigated later, between 1988 and 1989 (Bokelmann 1991). Both sites are dated to the Late Preboreal and cannot be separated by radiocarbon dating due to the Preboreal plateau in the calibration curve. However, palynological analysis carried out for both sites demonstrated that Wohnplatz 9 is older. In both cases large parts of the former occupation area were excavated and consisted of a central open fireplace surrounded by birch or aspen bark mats and distributions of charcoal and flint artefacts. Additional trenches in the adjacent shore zone provided only sporadic evidence of animal bones, so that hunting cannot have been of great importance on these sites. However, the microliths and microburins demonstrate that the production and/or repair of hunting weapons had taken place during the short time of occupation. The most striking difference between the two sites is that on the slightly younger Wohnplatz 8 , numerous burned hazelnut shells were recovered; however, according to the 


$$
\begin{aligned}
& * 2 \\
& \forall
\end{aligned}
$$




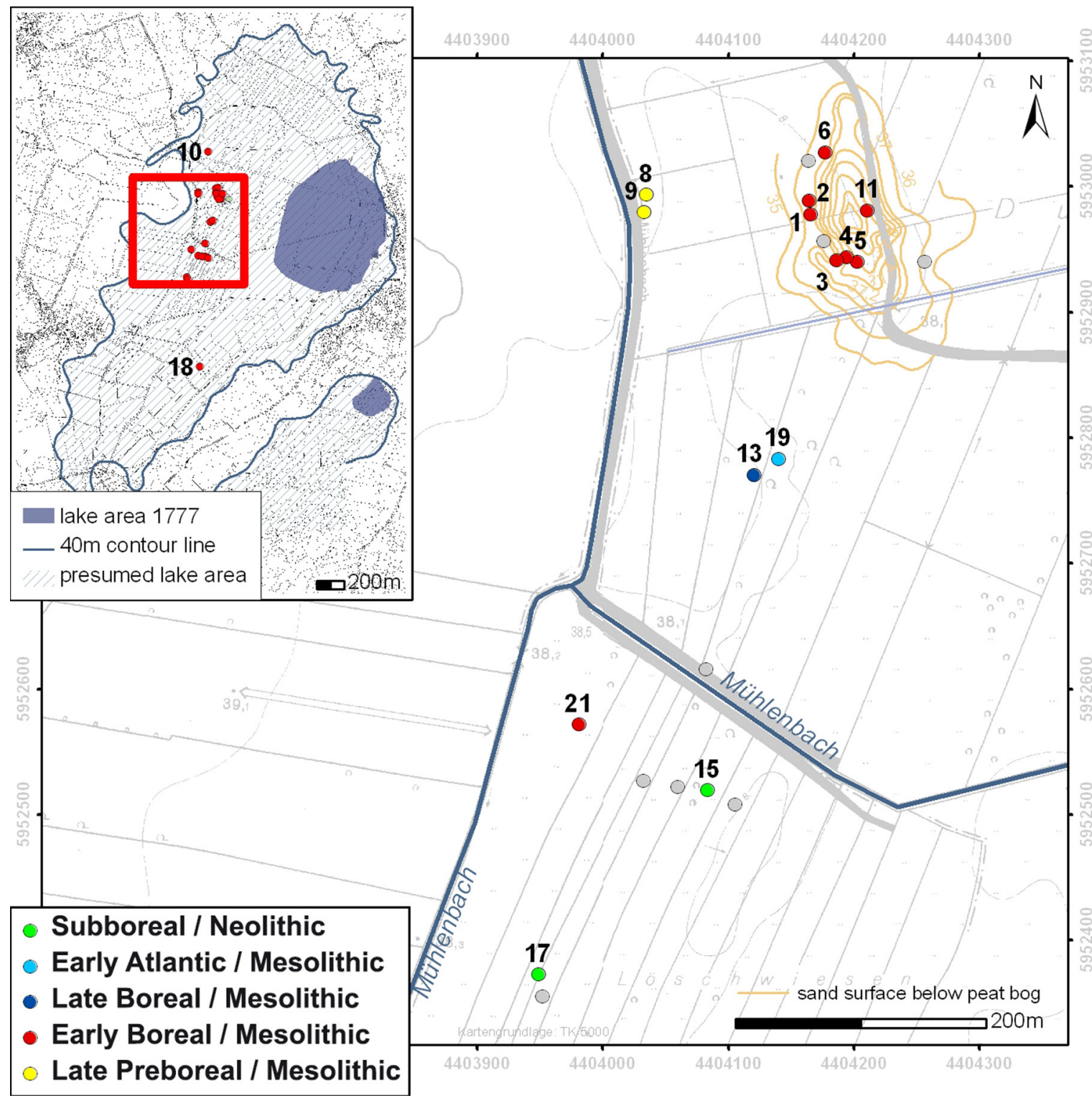

Figure 12.8: Overview of the different sites in the Duvensee bog with local site number and date (Illustration: J. Freigang and K. Göbel. Copyright Centre for Baltic and Scandinavian Archaeology, CC BY-NC 4.0).

palynological investigations, hazel initially only existed sporadically in the landscape. It can be concluded that because of the lack of burned hazelnut shells on Wohnplatz 9, the main reason for the initial occupation of the islands of Lake Duvensee was not the harvesting of hazelnuts and that this food was used as an addition to the diet when it appeared in the region.

The lithic technology is similar to the south Scandinavian sites and can be characterized as an industry dominated by irregular blades produced by hard hammer techniques from single platform or multi-platform cores: Techno complex 1 (Sørensen 2006). The microlith assemblage consists mainly of simple, partly obliquely or lateral retouched microlithic points and only a few have fully straight or convex retouched lateral edges: Phase

Figure 12.7 (page 322): The two antler frontlets from Bedburg-Königshoven (Photograph by J. Vogel. Copyright LVR-Landesmuseum Bonn, CC BY-NC 4.0). 
0 (Sørensen 2006). Adzes are prepared from flakes or from frost sherds and only a few irregular shaped core adzes exist. Burins and scrapers are rare.

The next youngest Mesolithic sites known so far in the Duvensee bog are situated on another small island approximately $150 \mathrm{~m}$ to the east of Wohnplatz 8 and 9, dating to the Early Boreal (Figure 12.8). The earliest ones (through palynological analysis) are Wohnplatz 1, 2 and 11 that date between c. 8800 and $8400 \mathrm{cal} \mathrm{BC}$ (Bokelmann 2012) and are therefore contemporaneous with the final occupation phase at Star Carr.

Duvensee Wohnplatz 2 was the first excavated Mesolithic site in the Duvensee bog by Schwantes in 1924 and 1926 (Schwantes et al. 1925; Schwantes 1928; Jenke 2009; Jenke 2011). Duvensee Wohnplatz 1 was investigated in 1946 by Schwabedissen (1949) and from 1966-1967 by Bokelmann (1971). Both sites are situated next to each other on the western shore of the island and consist of an approximately 4-5 $\mathrm{m}$ long and $3 \mathrm{~m}$ wide area covered by birch and pine bark mats and a central open fireplace. Several concentrations of flint artefacts and tools, charcoal and burnt and unburnt hazelnut shells were found around each fireplace. On Duvensee Wohnplatz 2, under the bark mats, an underlay of brushwood and sticks or branches was found (Schwantes et al. 1925; Jenke 2009). At Wohnplatz 1, wooden planks were found partly under the bark mats; these were split off from the outer part of larger trees (Bokelmann 1971, 11).

The lithic industry is still dominated by irregular blades produced from single or multi-platform cores and direct hard hammer techniques and soft direct hammer techniques (stone or antler) both exist: Techno complex 2 (Sørensen 2006). Flake and core adzes are present. Scrapers and lateral retouched blades and flakes are common; borers or burins are rare. The microlithic assemblages belong to the relative chronological phase 1 (Sørensen 2006). Simple partly retouched microlithic points still dominate and only a few points with fully lateral retouch or segments exist. The elongated trapezes ('Trapezspitzen') are noteworthy because Clark $(1954,102)$ describes these as a typical element for Star Carr. In addition scalene and isosceles triangles as well as triangles with a concave retouched shorter leg are present but in lower quantities than microlith points (Bokelmann 1971, 14-15).

Due to the acidic soil conditions in the occupation area, bone preservation was poor and only a few animal bones and artefacts were found. However, in 1926, Schwantes discovered a paddle made out of pine wood next to Wohnplatz 2 in the gyttja layers that should be the second-oldest one in Northern Europe after the piece from Star Carr (Chapter 29). However, recent radiocarbon dating revealed that it does not belong to Wohnplatz 2 but dates to a younger, Late Boreal occupation phase (Jenke 2009; Jenke 2011).

According to Bokelmann $(1971,13)$ the limited size of the occupied area and the relatively small number of artefacts are indicators of a short-term settlement. Because of the thick concentrations of cracked hazelnut shells the occupation must have taken place during August to September when hazelnuts are ripe. The other evidence suggests that people were carrying out bone and antler working and hunting weapons were being repaired and renewed.

Almost contemporary with Wohnplatz 1 and 2 is Wohnplatz 11, which was located next to the highest and driest spot of the former island. It was excavated by Bokelmann from 1996-2001 and is by far the most complex Mesolithic site in the Duvensee bog (Bokelmann 2012). What initially appeared to be a uniphase central fireplace of a larger settlement area turned out to be a multiphase structure that had accumulated intermittently over an extended period. It consists of a concentration of four hazelnut roasting hearths, bark-mat layers and incorporates small knapping areas with a diameter of about $4 \mathrm{~m}$ (Figure 12.9). The main period of activity spanned c. 250 years (Figure 12.2). Wohnplatz 11 was not occupied continuously throughout this period as peat had started to form over some bark mats but people may have returned to this location every few years before trees could hide it from view. This pattern is consistent with the number of bark-mat layers, which implies that the site was used on average at least once a decade. Soon after c. $8500 \mathrm{cal} \mathrm{BC}$ it was abandoned and the site was overgrown with peat. Although the construction of the hearths used for hazelnut roasting has been published (Lage 2004; 2011; Bokelmann 2012), due to the retirement of the excavator the site has not yet been finally published. These studies are currently being resumed under the auspices of the Centre for Baltic and Scandinavian Archaeology (ZBSA) as part of an interdisciplinary research project.

In summary, the excellent preservation of the Duvensee sites have provided a detailed insight into the development of the Early Mesolithic economy in Northern Europe. However, we have to be aware that the sites provide only a small insight into economic behaviour. Therefore it is problematic to use the sites for a reconstruction of the whole Early Mesolithic foraging strategy, suggesting that hazelnut exploitation is the main characteristic feature and meat was only of subsidiary importance (e.g. Holst 2010; 2014). As Bokelmann 


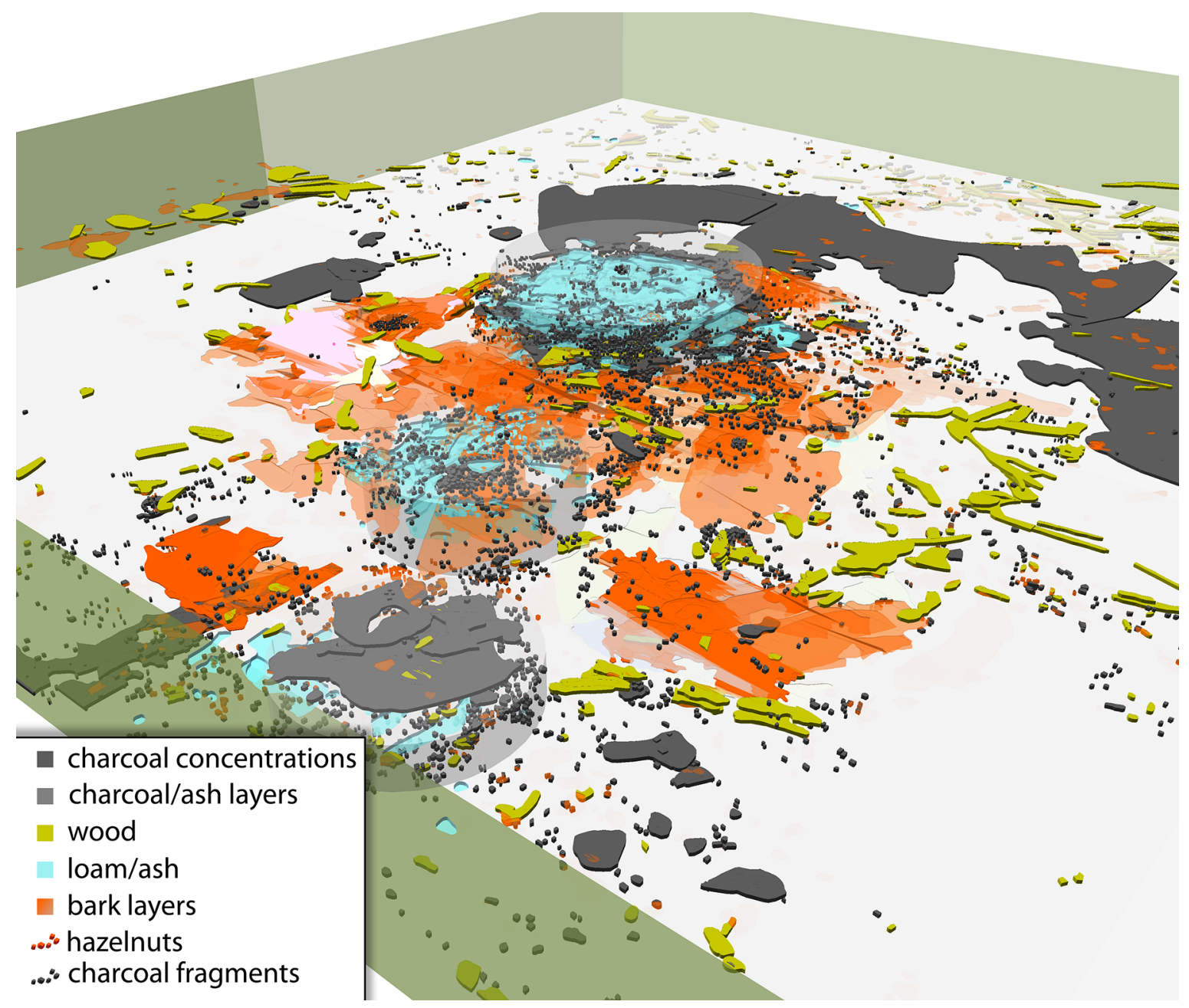

Figure 12.9: Duvensee Wohnplatz 11. Archaeological structures excavated from 1997-2001 in a 3D GIS model. This shows the position of the birch bark mats and of hazelnut roasting hearths in the excavation trench (Illustration: N. Binkowski, J. Freigang and K. Göbel. Copyright Centre for Baltic and Scandinavian Archaeology, CC BY-NC 4.0).

(2012) has shown, the quantity of hazelnuts which might be harvested cannot be predicted year to year due to changes in the weather. Therefore, it has to be questioned whether Mesolithic people established a special gathering technology which relied on nuts being stored as a surplus for the winter months or whether the Duvensee sites were used in a more opportunistic way and represent years of rich hazelnut harvests (Groß 2017).

\section{Friesack (Germany)}

Friesack is a micro-region in the state Brandenburg in Northeastern Germany where three sites from the Early Mesolithic are known and located in close proximity to each other. The most extensively excavated site is Friesack 4: this site was located on a former island in the middle of a wetland system. Most of the settlement site had been largely destroyed by sand quarrying in the 18th century. The first investigations began as early as 1916 by the amateur archaeologist Max Schneider (Gramsch 2002, 51-53). When Schneider had finished his work at the site in 1925 he was convinced that pottery was invented at Friesack during the Mesolithic due to ceramic finds associated with Mesolithic tool types. This was published in his 1932 book 'Die Urkeramiker' ('The Protoceramics') (Schneider 1932) but as was proven later, this interpretation had several shortcomings. 
In 1940 Hans Reinerth conducted further excavations at Friesack 4 which indicated that undisturbed layers with organic preservation were still present at the site, especially in the former shore area (Gramsch 1987a, 76). Plans for the lowering of the groundwater that would negatively affect the organic remains led to the most extensive excavation in the area which began in 1977 and lasted until 1989, focusing on the prehistoric shoreline (Gramsch 2002, 52-54). Further excavations were carried out in 1998, headed by Gramsch, and in 20002001 Stefan Wenzel excavated some remaining areas of the former settlement.

Among the vast amounts of organic finds from the excavations, Friesack 4 is characterized by stratified layers at the shore edge which included erosional phases which intersected with the accumulation of organic sediment and at least 65 events could be differentiated. This made it possible to connect the artefacts in these sediments to specific dryland settlement events which caused this erosion. Numerous radiocarbon dates proved the presence of Early Mesolithic people from the Middle Preboreal up to the Early Atlantic (Gramsch 2002, 64-65). Around 100,000 flint artefacts, 20,000 animal bones, 900 tools made from bone, antler or teeth, and almost 100 artefacts made from wood or bark, including net and rope fragments, have been recorded (Gramsch 2002, 65; 2016).

This extraordinary and extensive spectrum of finds is therefore key when comparing Early Mesolithic technology and typology for North and Central Europe, and particularly Star Carr. Because of the enormous number of bone and antler artefacts, including almost 391 bone points and fragments, Friesack 4 has contributed to our understanding of the typo-chronology of this important artefact category for the Early Mesolithic (Gramsch 1990; David 1999, David 2009; Gramsch 2011).

It is also important to note that like Star Carr, Friesack 4 was located close to a large water system (Groß in press) and is part of a settlement system with contemporaneous sites in the vicinity (Figure 12.10). One of these sites, Friesack 27a, was also located on what would have been an island. It was partly excavated during the 1980s in connection with the work undertaken at Friesack 4 and even though an area of only $38 \mathrm{~m}^{2}$ was investigated, a similar situation with layered sediments was recorded, though far less extensive. The occupation at this site starts in the Late Preboreal and ends during the Boreal when there was no longer connection to open water (Groß in press). The third site, Friesack 27b, is located on another former island and so far is only known from surface collections. From typology it is assumed that the site was also occupied during the Early Mesolithic but was probably used during the Late Mesolithic and Early Neolithic as well (Groß 2017, 86-90).

\section{Hohen Viecheln (Germany)}

Hohen Viecheln, located on the former shore of Lake Schwerin, was discovered in 1952 by children who found at least seven barbed points whilst playing. After test pitting, large excavations by Ewald Schuldt followed between 1953 and 1955 and uncovered more than 300 bone points. Minor-scale investigations were carried out in 1995 by Sigrid Schacht because of the restoration of an artificial channel ('Wallensteingraben') cutting through the site that was first constructed in the 16th century (Stuhr 1899) and resulted in the destruction of the main parts of the prehistoric settlement. In these excavations it was shown that undisturbed layers still existed below the base of the channel. In 2016 the ZBSA took sediment cores to investigate the environmental development of the prehistoric shoreline (Groß et al. in press b).

Due to the large number of bone points, Hohen Viecheln is seen as a key site for the Southern Maglemosian, even though it was noted during the excavation and in Schuldt's monograph (1961) that the site has to be split into several chronological layers and therefore does not reflect a single occupation. The palynological analysis by Schmitz (1961) is especially important for the understanding of the site's chronology because these dated the main occupation phase to the Late Boreal and Early Atlantic with two earlier phases in the Late Preboreal and Late Preboreal/Early Boreal transition. More than 10,500 artefacts made from flint, almost 350 bone tools and several other finds represent a chronological span from the Early Mesolithic to the Neolithic. Still most of the finds originate from Mesolithic layers and especially the bone and antler artefacts are important in this respect because of their typo-chronological value and technological information (David 1999; David 2009). However, due to complex stratigraphic information (Schüle 1962; Gramsch 1964; Pratsch 2006) it has not been possible to obtain a sound chronological framework for dating the finds indirectly (Groß et al. in press b). Therefore, almost 40 radiocarbon dates have been obtained from bone artefacts to understand the chronology and stratigraphy at Hohen Viecheln (Wild in press; Groß et al. in press b). The majority of the organic finds actually date to the Early Mesolithic and thus provide an insight into the chronology of different forms of organic artefacts 


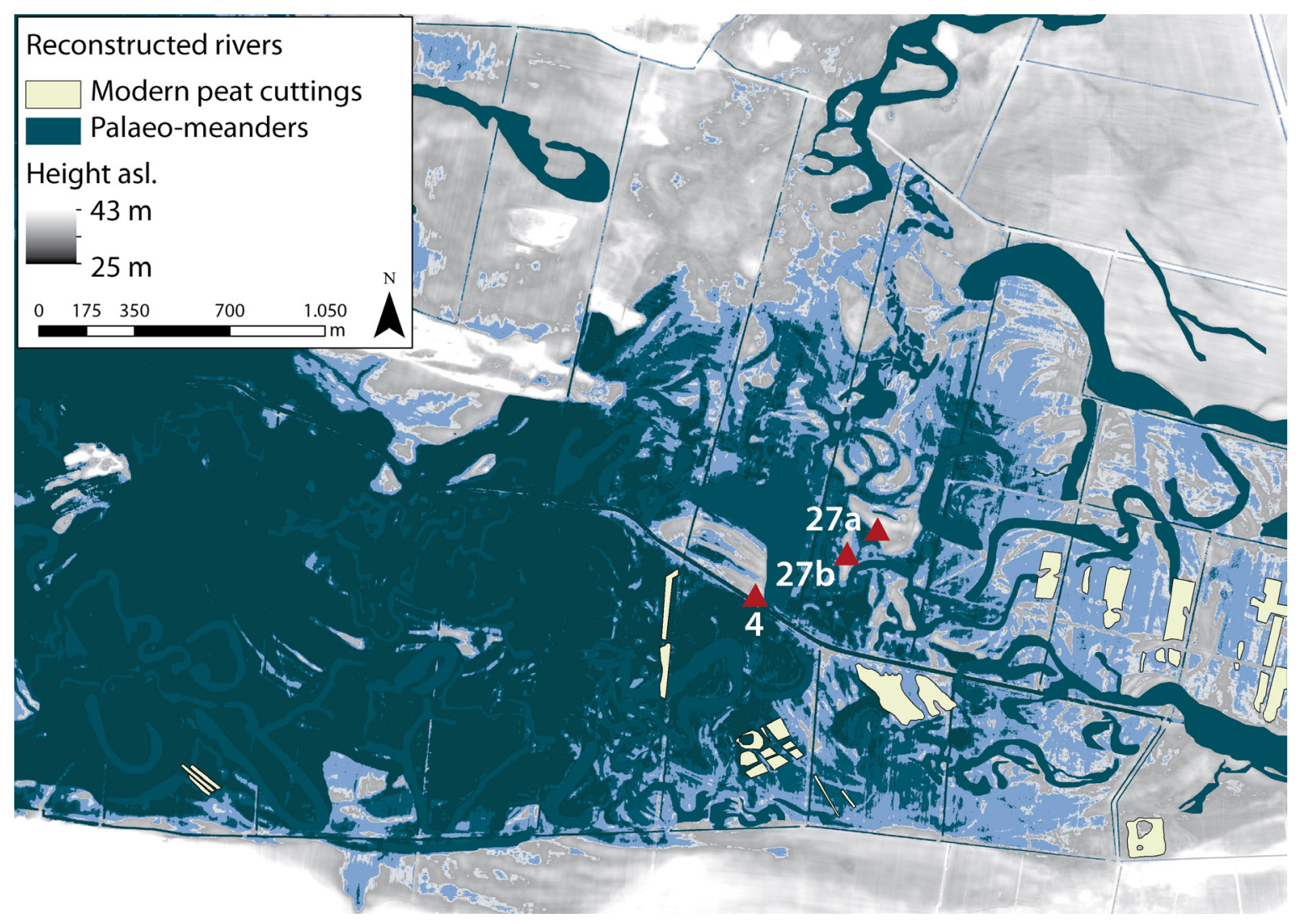

Figure 12.10: Modelled water levels and geomorphology show the rivers that existed during the Preboreal around Friesack. It is also evident that the sites were situated on islands or in island-like locations. The sites are indicated by red triangles with their respective number (Reprinted from Groß 2017, Abb. 22; geobasisdata: () GeoBasis-DE/LGB (2013)).

in North-eastern Germany at that time. One of the notable finds from the site is an antler frontlet, comparable to those found at Star Carr (see Chapter 26), and this too was dated to the Preboreal.

\section{Rothenklempenow (Germany)}

The site of Rothenklempenow lies on the edge of a former lake and was excavated from 1982 to 1993 by Sigrid Schacht. The significant artefact spectrum recorded during the early phases of work motivated the excavator to extend the trenches into the lower-lying areas towards the former lake (Schacht 1993, 112-113; Schacht and Bogen 2001, 6). The excavations indicated the existence of two settlement areas and an Early Mesolithic refuse zone in the adjacent lake. The organic preservation, especially in the refuse zone, had preserved a wide range of organic materials, notably the bones of fish, animals and humans, as well as artefacts such as a baton de commandement/Lochstab, bark floaters and remains of nets, bone points and pendants made from teeth (the latter exhibiting typical decoration for the Maglemose culture) (Schacht 1993, 116). The settlement area next to the excavated refuse zone consisted of two layers containing Neolithic and Mesolithic material. In the other settlement area a grave of a c. 50-year-old woman was found and stratigraphically dated to the Late Mesolithic (Schacht 1993, 117; Bach and Bruchhaus 1995). After a break of six years, new excavations in Rothenklempenow were conducted in 1999 and the spectrum of artefacts was increased by further finds (Schacht and Bogen 2001). The site is clearly an important one, but to date extensive analysis and publication of the material is still lacking. 


\section{Discussion}

Due to the differential taphonomy of sites in Southern Scandinavia, two chronologies have been established for the Preboreal: an absolute one developed from radiocarbon dating of the bone deposits and a relative chronology that is mainly developed from the lithic assemblages and in particular the microliths excavated at habitation sites. However, these two chronologies do not always provide the same interpretations of Preboreal Mesolithic society and its development.

It is particularly problematic that we still have no radiocarbon evidence for habitation sites in Southern Scandinavia before the Middle Preboreal period. Dating of reindeer bone from the site of Stellmoor suggests early Late Glacial/Preboreal hunting close to Southern Scandinavia, yet the cultural attribution of these hunters is not absolutely clear. At the same time the early date for an elk antler adze of clearly Mesolithic type from the Lundby kettle hole (LM1) suggests an appearance of Maglemosian people in the very first part of the Preboreal, or even the earlier Younger Dryas, although as discussed, this date could be too old. In central Jutland the site of Nørregaard VI appears to date, based on typology and technology, to the Palaeolithic-Mesolithic transition and to an affiliation with the Epi-Ahrensburgian/Long Blade complex (that has its distribution in Western Europe). Therefore, it might be the case that several culturally diverse groups inhabited these Early Preboreal landscapes and were mobile in relation to seasons and game. Moreover, it could be the case that these different, very early Preboreal groups related differently to the various landscapes and their particular biotopes: in the early forested Weichsel moraine landscape in eastern part of Southern Scandinavia we see the Maglemose group, whilst in the more open steppe Saale moraine landscape of Western Europe the Epi-Ahrensburgian group seems to be found.

Star Carr is one of our earliest Mesolithic habitation sites but it does not seem to belong to a highly mobile group of hunter-gatherers, as suggested by the sparse remains of some of these other locations in the very first part of the Preboreal period. Instead, Star Carr connects in many aspects to the earliest Maglemose habitation sites found in Southern Scandinavian and Northern Germany. In Southern Scandinavia we are still hoping for the excavation of a Preboreal wetland habitation site with good preservation because only through the comparison of well-preserved material and better radiocarbon dating of such a site can we begin to better understand the connection between Star Carr and the related Southern Scandinavian sites.

South of Scandinavia, a slightly clearer picture can be drawn, due to the larger number of radiocarbon dated sites in Northern Germany. While there are no sites with Mesolithic technocomplexes before the Middle Preboreal in the central part of the North German Plain, evidence for Early Preboreal Mesolithic sites are known further south from the Cologne Lowland. Therefore, it can be assumed that Mesolithic traditions were introduced from the south and successively spread towards the north so that the Maglemosian developed. While the general appearance of the Early Maglemosian technocomplex is quite uniform especially from a lithic technology point of view, several regional differences become evident when organic artefacts are examined (e.g. David 1999; Cziesla 2006).

One of the important ways in which we can understand past human behaviour is through an examination of the economy. The importance of well-excavated wetland sites like Star Carr should not be underestimated: even though several sites with good organic preservation have been found in Denmark and Northern Germany, the subsistence economy is insufficiently understood. For instance, while some sites have produced important hunting and fishing tools, the amount of fish found on Maglemosian sites still remains very low despite the fact that aquatic fish were clearly important as a food resource, as new studies on stable isotopes of Early Holocene human remains show (Fischer 2007; Fischer et al. 2007; Terberger et al. 2012; Drucker et al. 2016; van der Plicht et al. 2016). We also know little about the role of plants in the subsistence economy; however, for the Late Preboreal in Germany we do see the use of hazelnuts, although in Scandinavia an abundance in hazel does not appear until the onset of the Boreal.

In sum, the main problem that we currently face is understanding the earliest part of the Preboreal in Northern Europe: we still lack finds and dates that can help us to see how Mesolithic people established themselves in the landscapes of Northwest Europe, or what we can term 'the process of Mesolithic colonisation'. However, part of this problem is also linked to how we define the Mesolithic period. One approach is to follow the geological epochs and define the first Mesolithic with the first anthropogenic Holocene date. However, if we insist on a definition that incorporates the humanities, we need to consider the Mesolithic as representing a clear shift in how people lived, engaged in and perceived their world. Perhaps then, the first Preboreal 
habitation sites that demonstrate local resource exploitation in terms of lithics, fauna and plant materials are also the ones that we should define as our first Mesolithic sites. For example, at the sites of Star Carr, Friesack, Duvensee and Barmosen 1, we see the earliest evidence of people who had gained specific knowledge of the particular regional landscape and therefore had the possibility to stay within the same landscape for years and even generations. Indeed, these sites represent populations that colonised the Northwest European landscapes and which we can therefore define as representing the first Mesolithic societies of this area. At the same time, we have to remember that these people were probably also the ones to colonise further into Northern Scandinavia, for example along the coast of Norway, though this time in a very different marine and environmentally subarctic landscape. 
